\title{
ANALISIS MAKNA DENOTATIF DAN KONOTATIF DALAM FILM UPIN \& IPIN EPISODE KENANGAN MENGUSIK JIWA
}

\author{
Juprinedi $^{(1)}$,Arta Uly Siahaan ${ }^{(2)}$, dan Cahya Miranto(3) \\ Teknik Informatika, Politeknik Negeri Batam \\ Jl.Ahmad Yani, Batam Kota, Kota Batam, Kepulauan Riau, 2946 I, Indonesia \\ Email: (I) JUPRINEDI.43 | I2I I05 |@student.polibatam.ac.id, (2) arta@polibatam.ac.id,
}

(3) cahya@polibatam.ac.id

\begin{abstract}
Abstrak
Representations of public life in recalling past events or history can be found, among others, in 3D animated films. An interpretation of connotative meaning, as the second layer meaning, arises when a symbol is associated with its psychological aspects, such as feelings, emotions, or beliefs, which are closely related to culture, knowledge, and history. This study aims to interpret symbols in the Kenangan Mengusik Jiwa episode of Upin \& Ipin animated film for their denotative and connotative meaning to better understand the context of the story and the moral message conveyed. A questionnaire was used in this research to increase validity. In processing questionnaire data, a calculation is conducted using the Likert scale. The results of the study indicate that the main moral message conveyed in this episode is to never forget history or established culture. This interpretation is supported by results from questionnaire data.
\end{abstract}

Keywords : connotative meaning, denotative meaning, animation

\section{PENDAHULUAN}

Sisi unik dari sebuah film animasi adalah kemampuannya mengangkat sisi-sisi lain yang luput dari pandangan kita. Selain itu, karakter dalam film animasi bisa melakukan gerakan-gerakan yang tidak bisa dilakukan manusia. Dalam penelitian yang berjudul Semiologi Roland Barthes, Kumiawan (2001) menyebutkan bahwa semiotika merupakan suatu studi ilmu atau metode analisis untuk mengkaji tanda-tanda dalam suatu konteks skenario, gambar, teks, dan adegan di film agar menjadi sesuatu yang dapat dimaknai. Objek-objek tidak hanya membawa informasi, tetapi juga itu hendak berkomunikasi. Hal ini karena objek tersebut mengkonstitusi sistem terstruktur dari tanda yang digunakan dalam film.

Film animasi 3D Upin \& Ipin adalah salah satu dari film animasi yang bisa memberi gambaran mengenai kehidupan pedesaan, yang dengan kesederhanaannya tetap penuh dengan nilai-nilai budaya-bagaimana moral dan didikan yang baik diterapkan kepada anak-anak, kekeluargaan dijunjung tinggi, serta toleransi beragama dan pesan-pesan moral yang secara gamblang bisa diterima oleh masyarakat. Episode yang akan dianalisis adalah Kenangan Mengusik Jiwa, yang merupakan episode 34, 35, dan 36 yang dirilis pada tanggal 16 Desember 2012. Episode ini banyak menonjolkan seni dan budaya serta nilai-nilai lainya yang diperkenalkan kembali kepada generasi muda. Film ini banyak memunculkan simbol-simbol dan dialog-dialog sinematografi yang memiliki makna. Berdasarkan paparan di atas, permasalahan yang akan dibahas adalah mengetahui bagaimana simbol-simbol sinematografi digunakan di dalam film animasi 3D Upin \& Ipin episode Kenangan 
mengusik Jiwa, guna mendalami pesan-pesan moral yang hendak disampaikan kepada penonton bedasarkan semiotika Roland Barthes. Lebih lanjut, penelitian ini juga bertujuan untuk mengetahui sejauh mana penonton memahami pentingnya analisis semiotika pada film animasi 3D Upin \& Ipin episode Kenangan mengusik Jiwa.

Penelitian Rawung (2013) yang berjudul Analisis Semiotika pada Film Laskar Pelangi sukses menjabarkan pesan-pesan dan makna yang terkandung dalam film Laskar pelangi. Dalam penelitian ini disebutkan bahwa bahasa yang digunakan dalam film Laskar Pelangi adalah bahasa yang bisa memberikan makna positif. Selain penggunaan bahasa, dittinjau dari semiotika gerak, film Laskar Pelangi dapatt membangun moral yang tinggi bagi penontonnya. Secara umum, tersirat pesan mengenai bagaimana didikan yang seharusnya dilakukan kepada generasi penerus bangsa dan saran bagi para produser dan sutradara agar bisa lebih meningkatkan mutu pendidikan dalam sebuah karya.

Tidak jauh berbeda, Widianingrum (2012) dalam penelitiannya Rasisme Dalam Film Fitnah (Analisis Semiotika Di Dalam Film Fitnah), mampu menunjukkan representasi perilaku, sikap, ataupun tindakan rasisme yang terdapat di dalam film Fitnah. Hal ini menggambarkan bahwa sebuah film dapat digunakan sebagai sarana untuk mengemukakan pendapat, pemikiran, ataupun idealisme seseorang dan sebagai pembelajaran kemanusiaan setiap individu di dunia bahwa perbedaan tidak selalu dijadikan suatu permasalahan apalagi alasan untuk saling menghancurkan satu dengan yang lainya.

Pada dasarnya, penanda konotasi dibangun dari tanda-tanda dari sistem denotasi. Makna konotasi merupakan penciptaan makna lapis kedua yang terbentuk ketika lambang denotasi dikaitkan dengan aspek psikologis, seperti perasaan, emosi, atau keyakinan dan memiliki hubungan yang sangat dekat dengan budaya, pengetahuan, dan sejarah. Semiotika (disebut juga studi semiotik atau semiologi dalam tradisi Saussurean) adalah studi tentang makna keputusan, yang termasuk studi tentang tanda-tanda dan proses tanda (semiosis), indikasi, penunjukan, kemiripan, analogi, metafora, simbolisme, makna, dan komunikasi. Semiotika berkaitan erat dengan bidang linguistik, yang mempelajari struktur dan makna bahasa secara lebih spesifik. Namun, berbeda dari linguistik, semiotika juga mempelajari sistem-sistem tanda non-linguistik. Semiotika sering dibagi menjadi tiga cabang: Semantik, Sintaksis, dan Pragmatik. Semantik adalah hubungan antara tanda dan hal-hal yang mereka lihat (denotata/makna). Sintaksis merupakan hubungan antara tanda-tanda dalam struktur formal. Pragmatik adalah hubungan antara tanda dengan agen.

\section{METODE}

Penelitian ini bersifat kualitatif dan kuantitatif. Dalam penelitianya, Rahmat (2009) menerangkan bahwa metode penelitian kulitatif adalah metode penelitian yang berlandaskan pada filsafat postpositivisme, digunakan untuk meneliti pada kondisi objek yang alamiah, (sebagai lawan dari eksperimen) dan peneliti sebagai alat kunci. Pengambilan sampel sumber data dilakukan secara purposif dan snowball. Analisis data bersifat induktif/kualitatif dan hasil penelitian kualitatif lebih menekankan makna daripada generalisasi. Setidaknya terdapat lima tahapan sebagai patokan dalam penelitian kualitatif: mengangkat permasalahan, memunculkan pertanyaan, mengumpulkan data yang relevan, melakukan analisis data, dan menjawab pertanyaan penelitian.

Penelitian akan mengambil adegan-adegan dari film animasi 3D Upin \& Ipin episode Kenangan Mengusik Jiwa yang mengandung penggambaran terhadap pesan-pesan sesuai dengan konsep dan kategori yang menjadi acuan peneliti. Analisis dilakukan per scene yang menunjukkan penggambaran pembelajaran pesan-pesan yang disampaikan dalam film, yang kemudian dianalisis mulai dari makna denotasi dan konotasi yang mengandung 
penggambaran pembelajaran budi pekerti. Setelah itu dilakukan pengambilan data dengan menggunakan kuesioner untuk mengetahui sejauh mana respon penonton tentang analisis semiotika untuk dapat diambil suatu kesimpulan tentang penggambaran makna beserta pesan-pesan yang disampaikan.. Diagram alir pelaksanaan analisis disajikan pada gambar 1 .

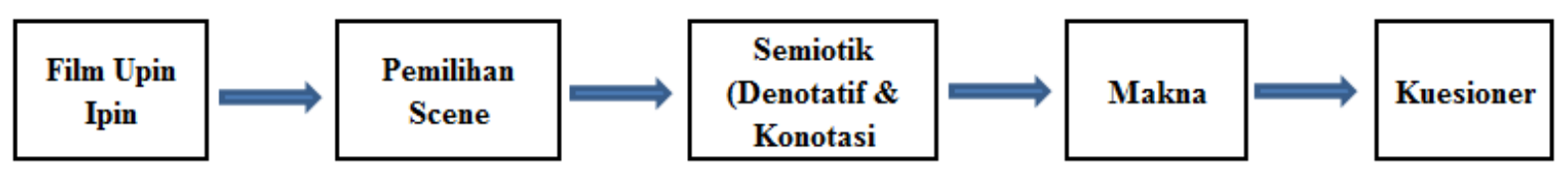

Gambar 1 Diagram Alir Pelaksanaan Analisis

Metode penelitian kuantitatif merupakan salah satu jenis penelitian yang sistematis, spesifik, terstruktur, dan juga terencana dengan baik dari awal hingga mendapatkan sebuah kesimpulan. Penelitian kuantitatif lebih menekankan pada penggunaan angka-angka, yang membuatnya menjadi lebih mendetail dan lebih jelas. Selain itu, penggunaan tabel, grafik, dan juga diagram sangat memudahkan untuk dibaca. Dari berbagai metode kuantitatif yang ada, dalam penelitian digunakan metode survei, yang relevan dalam pengambilan data untuk mendapatkan kesimpulan dari hasil analisis.

Dalam mengolah data kuesioner, digunakan penghitungan kuesioner dengan menggunakan skala Likert. Skala Likert adalah skala yang digunakan untuk mengukur persepsi, sikap, atau pendapat seseorang atau kelompok mengenai sebuah peristiwa atau fenomena sosial, berdasarkan definisi operasional yang telah ditetapkan. Skala ini merupakan suatu skala psikometrik yang biasa diaplikasikan dalam angket dan paling sering digunakan untuk riset yang berupa survei, termasuk dalam penelitian survei deskriptif.

Skala Likert kerap digunakan sebagai skala penilaian karena memberi nilai terhadap sesuatu. Skala Likert bertujuan untuk mengukur kesetujuan dan ketidaksetujuan seseorang terhadap suatu objek penelitian. Skala Likert juga biasa disebut skala sikap, yang menunjukkan sikap setuju atau tidak setuju terhadap sesuatu, yang dalam peneltitan ini dibagi dalam lima kategori: Sangat Baik, Baik, Cukup Baik, Kurang Baik, dan Sangat Kurang Baik. Interpretasi berdasarkan KBBI merupakan pemberian kesan, pendapat, atau pandangan teoritis terhadap sesuatu. Maka, dalam skala likert, interpretasi skor bertujuan untuk menerjemahkan dan memberi makna terhadap skor yang diperoleh dari orang yang diuji atau responden. Pernyataan yang ada dalam skala Likert hanya dua: pernyataan positif dan negatif. Berikut cara menghitung hasil pengamatan secara manual menggunakan skala Likert:

Skor untuk responden yang menjawab Sangat Setuju (4) : Jumlah responden x 4

Skor untuk responden yang menjawab Setuju (3): Jumlah responden x 3

Skor untuk responden yang menjawab tidak Setuju (2) : Jumlah responden x 2

Skor untuk responden yang menjawab Sangat tidak Setuju (1): Jumlah responden x 1

Jumlah skor ideal untuk pertanyaan yang diajukan kepada responden :

Skor tertinggi : 4 (Sangat Setuju) x jumlah responden

Skor terendah : 1 (Sangat tidak Setuju) x jumlah responden

Interpretasi skor hasil pengamatan : (Jumlah skor ideal / skor tertinggi) x 100\%

Gambar 2 mengilustrasikan hasil penghitungan secara umum. 


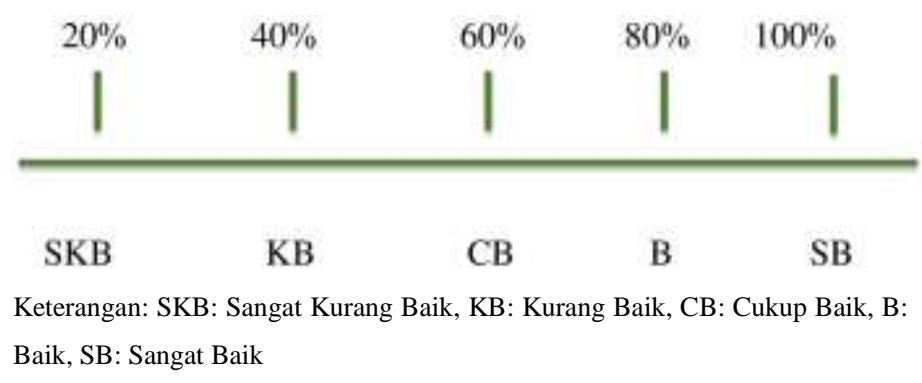

Gambar 2 Hasil Penghitungan

\section{HASIL DAN PEMBAHASAN}

Film animasi yang menjadi penelitian penulis ini berjudul Upin \& Ipin episode Kenangan Mengusik Jiwa dan berdurasi 20 menit. Film animasi ini mengisahkan mengenai dua anak kecil kembar yang sedang berkunjung ke rumah tetangganya yang biasa disebut Atok Dalang. Atok Dalang ini digambarkan sebagai seorang kakek yang hidup sendiri karena sanak keluarganya merantau jauh. Hal tersebut diceritakan pada episode Upin \& Ipin yang lainnya. Upin \& Ipin dan sang Atok pun menyaksikan film yang tengah diputar di televisi milik Atok. Film tersebut adalah film legendaris yang sangat terkenal di Malaysia, P. Ramlee. Ternyata, film bergambar hitamputih itupun menyihir kedua anak kembar tadi menjadi pecinta film P. Ramlee. Bahkan, mereka dan temantemanya menirukan dialog seperti yang ada pada film tersebut. Hingga pada suatu hari, mereka bertemu dengan sosok Datuk Abdul Azez Sattar bin Sattar atau biasa dikenal dengan Datuk Azez Satar. Seorang aktor legendaris dari Malaysia yang turut berperan dalam film P. Ramlee di warung Paman Muthu.

Pada dasarnya, bahasa yang digunakan dalam film animasi ini adalah bahasa melayu Malaysia. Sehingga banyak tuturan pada dialog di film ini yang kurang dapat dipahami dengan baik oleh sebagian masyrakat di Indonesia. Berdasarkan KBBI, arti dari kenangan adalah sesuatu yang membekas dalam ingatan. Sedangkan salah satu arti dari mengusik adalah mengganggu, mencampuri urusan orang lain. Namun, jika diartikan sesuai dengan bahasa melayu, mengusik berarti menyentuh. Namun, arti menyentuh ini juga terdapat dalam KBBI. Terakhir, kata jiwa menurut KBBI mempunyai makna yang sama dengan bahasa Melayu, yaitu raga, orang yang semangat, dan utuh. Jika digabungkan, Kenangan Mengusik Jiwa berarti sebuah kejadian indah, atau peristiwa di masa lampau yang sangat membekas di ingatan seseorang sampai saat ini. Hal ini sesuai dengan jalan cerita yang ditampilkan pada episode ini. Film P. Ramlee yang sudah legendaris sejak puluhan tahun lalu di Malaysia ini, tentu masih membekas di ingatan masyarakat Malaysia. Di Indonesia sendiri, P. Ramlee merupakan aktor Malaysia yang tersohor. Tak hanya di negerinya, di Indonesia, P. Ramlee juga memiliki nama yang harum. Apalagi, di Aceh ia memiliki tali-temali dengan daerah di ujung barat Indonesia itu.

Hanya enam scene yang dianalisis dalam penelittian ini. Keenamnya merupakan scene yang dianggap paling bisa mewakili inti dari keseluruhan cerita. Dari keenam scene yang penulis ambil sebagai bahan penelitian, terlihat saling keterkaitan antar-scene di dalam film animasi ini dalam membentuk sebuah wacana di lingkungan masyarakat. Seluruh jenis wacana, baik yang berupa narasi, deskripsi, maupun argumentasi, tidak berdiri sendiri-sendiri melainkan saling berkesinambungan dalam membentuk cerita yang layak untuk dinikmati semua kalangan. Unsur kebudayaan dan pesan moral yang tertuang secara tersirat dalam animasi ini juga merupakan hal yang sangat positif dan merupakan sebuah pengajaran dan pembelajaran yang dapat mengingatkan penonton bahwa korelasi antara budaya dan sejarah adalah sesuatu yang tidak dapat dipisahkan dan dilupakan. 
Dalam scene pertama ini, Upin dan Ipin bertamu ke rumah Tok Dalang dengan membawa makanan. Setelah memanggil Tok Dalang dan tidak ada jawaban, maka Upin pun membuka perlahan pintu rumah Atok dengan memberi salam. Analisis scene 1 disajikan pada tabel 1.

Tabel 1 Analisis Scene 1

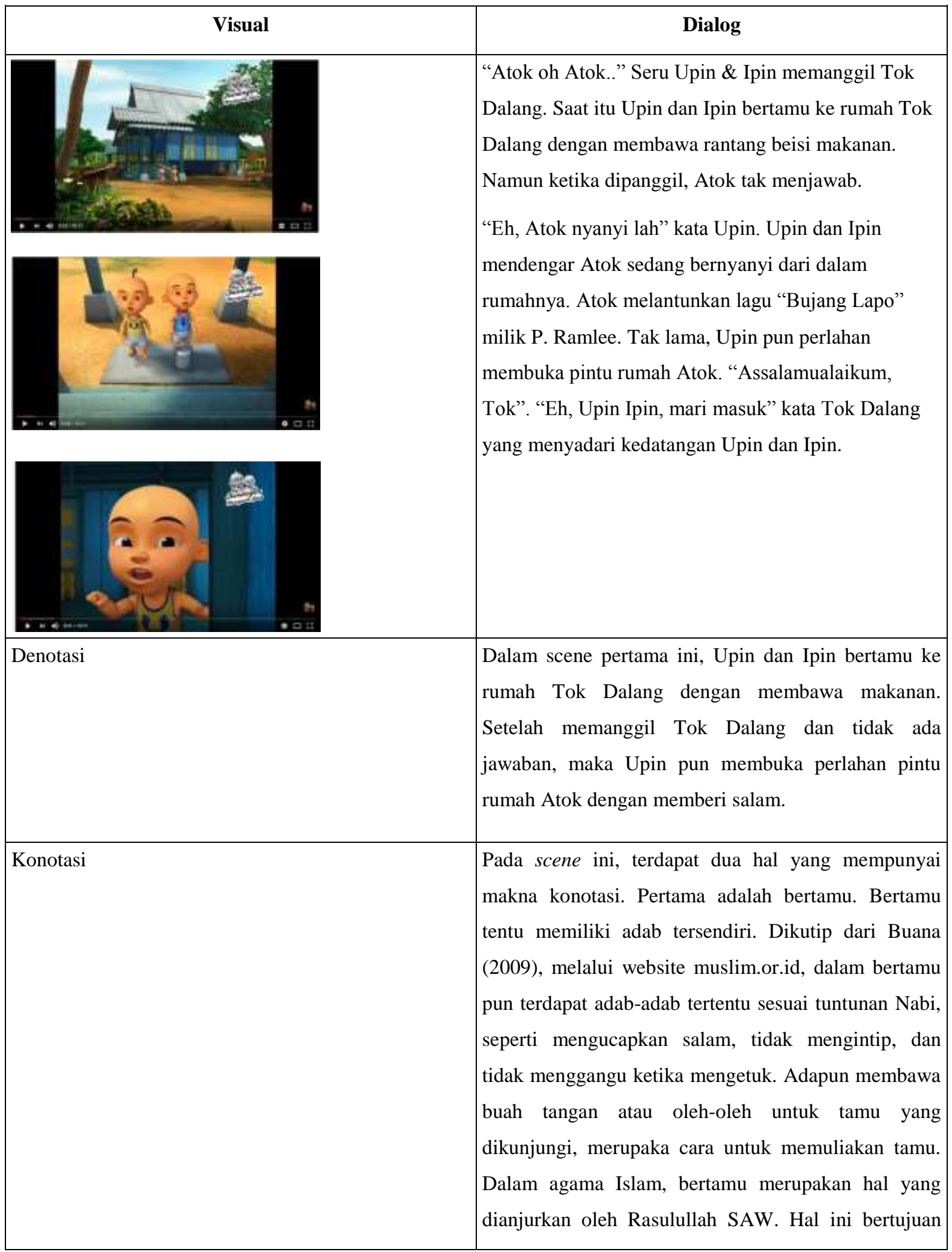


untuk mempererat tali silaturhami antar tetangga. Mengucapkan salam juga merupakan salah satu hal yang sangat penting ketika bertamu. Dalam scene ini, Upin dan Ipin mengucapkan Assalamualaikum. Salam menurut Kamus Bahasa Indonesia, artinya damai; pernyataan hormat; dan ucapan assalamualaikum warahmatullahi wabarakatuh. Dalam perspektif Islam, mengucapkan salam assalamu'alaikum warahmatullahi wabarakatuh atau ringkasnya assalamu'alaikum artinya menyampaikan pesan damai, rasa hormat, dan doa Assalamu'alaikumwarahmatullahi wabarakatuh artinya "Semoga keselamatan, keberkahan, dan kasih sayang (rahmat) dari Allah SWT menyertai Anda/kalian".

Salah satu aspek utama yang terdapat dalam sebuah film adalah setting. Setting yang digunakan dalam sebuah film umumnya dibuat senyata mungkin dengan konteks ceritanya sehingga hal ini mampu meyakinkan penonton bahwa seolah-olah cerita yang terjadi nyata. Setting yang digunakan pada scene kedua adalah penggunaan warna hitam putih pada animasinya. Hal ini bertujuan untuk membuat seolah-olah film tersebut merupakan film pada masa lalu. Analisis scene 2 disajikan pada tabel 2.

Tabel 2 Analisis Scene 2

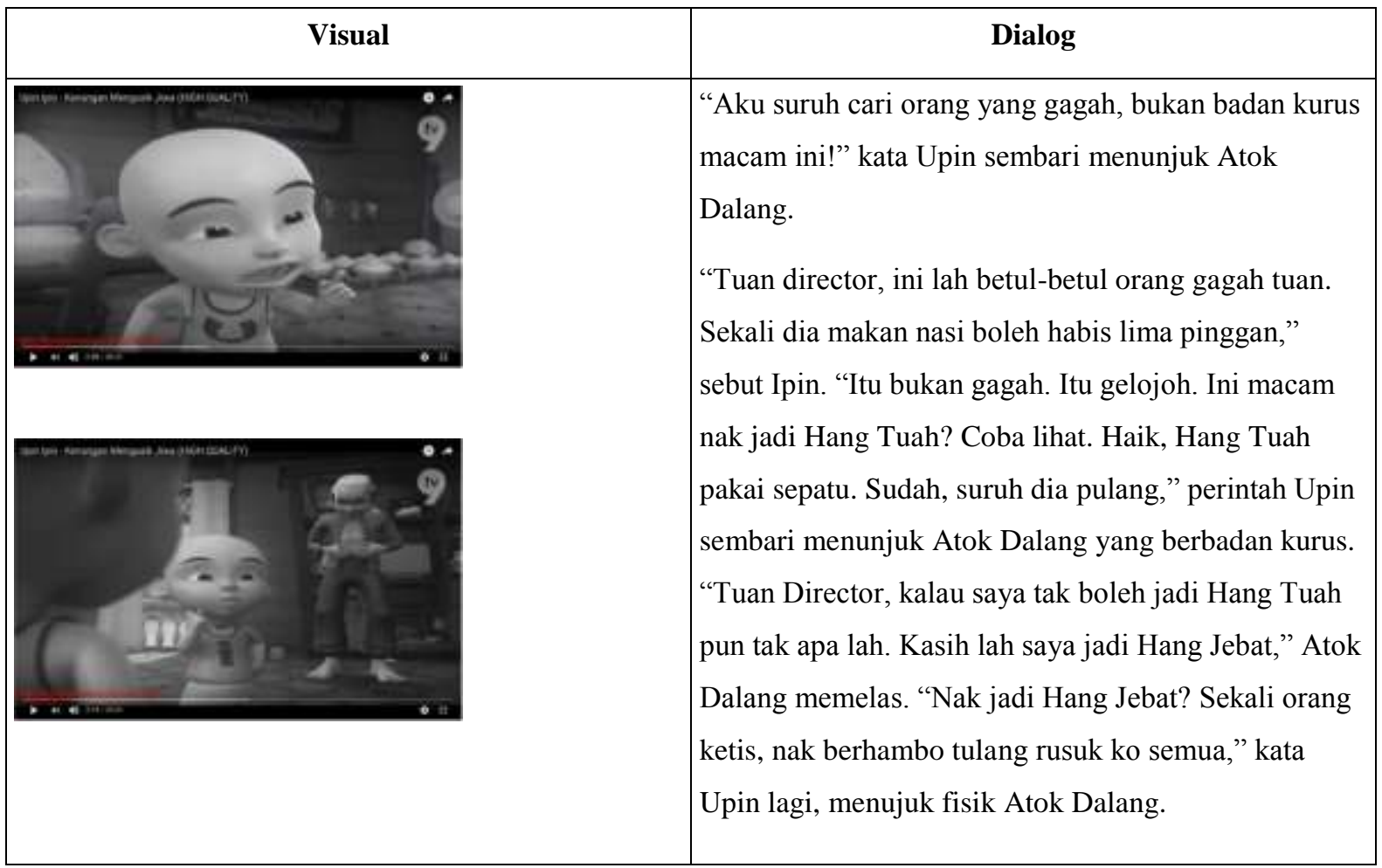




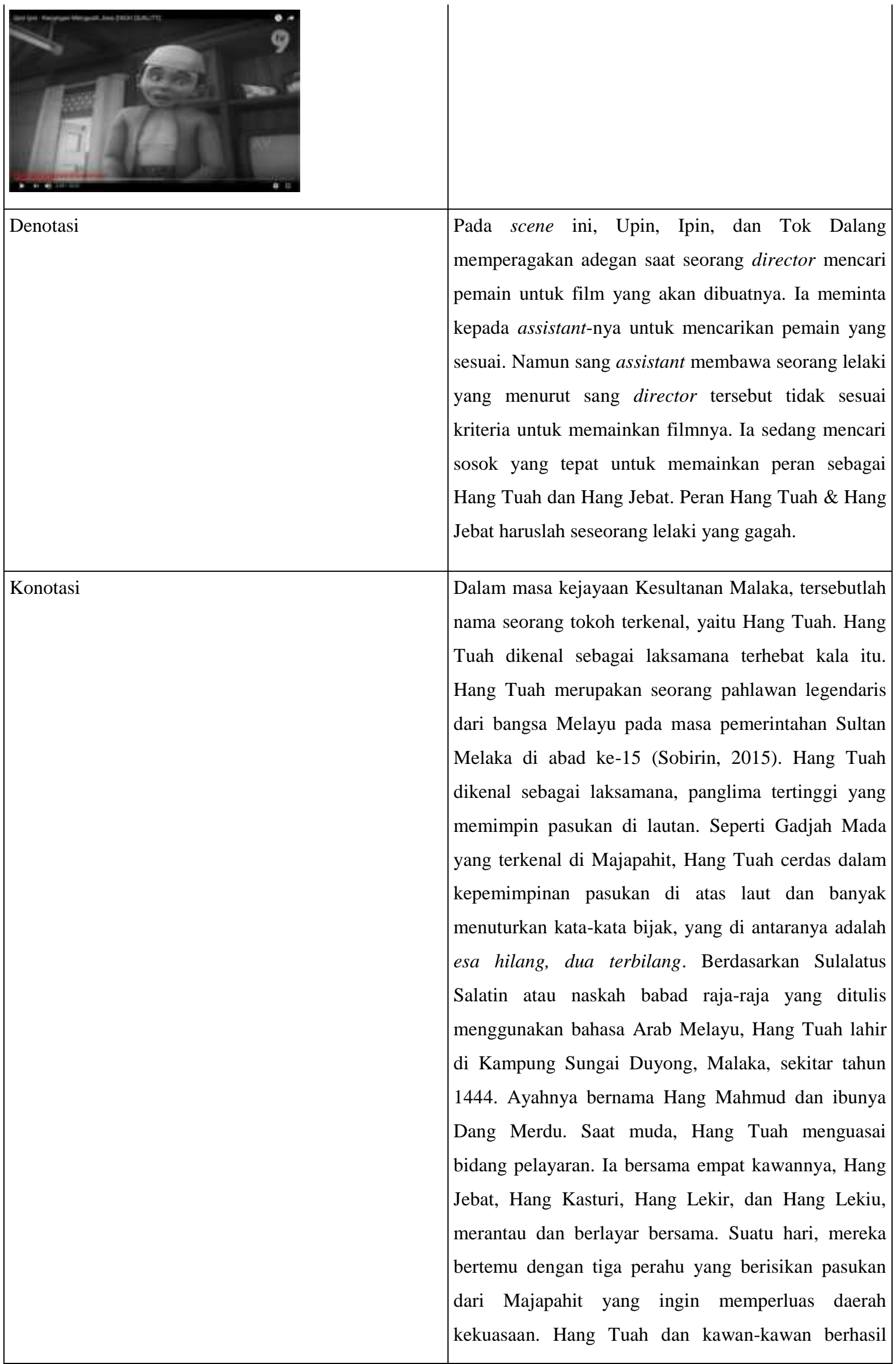


menundukkan rombongan perahu tersebut. Kemudian, karena prestasinya, bendahara (setingkat perdana menteri) mengangkatnya menjadi laksamana di Malaka.

Di scene ketiga, Upin dan Ipin ikut menyaksikan film P. Ramlee bersama Tok Dalang. Pada scene ini, terlihat Upin \& Ipin sangat antusias terhadap film ini. Mereka pun tertawa terbahak-bahak menyaksikan film P. Ramlee yang berjudul Seniman Bujang Lapok. Analisis scene 3 disajikan pada tabel 3.

Tabel 3 Analisis Scene 3

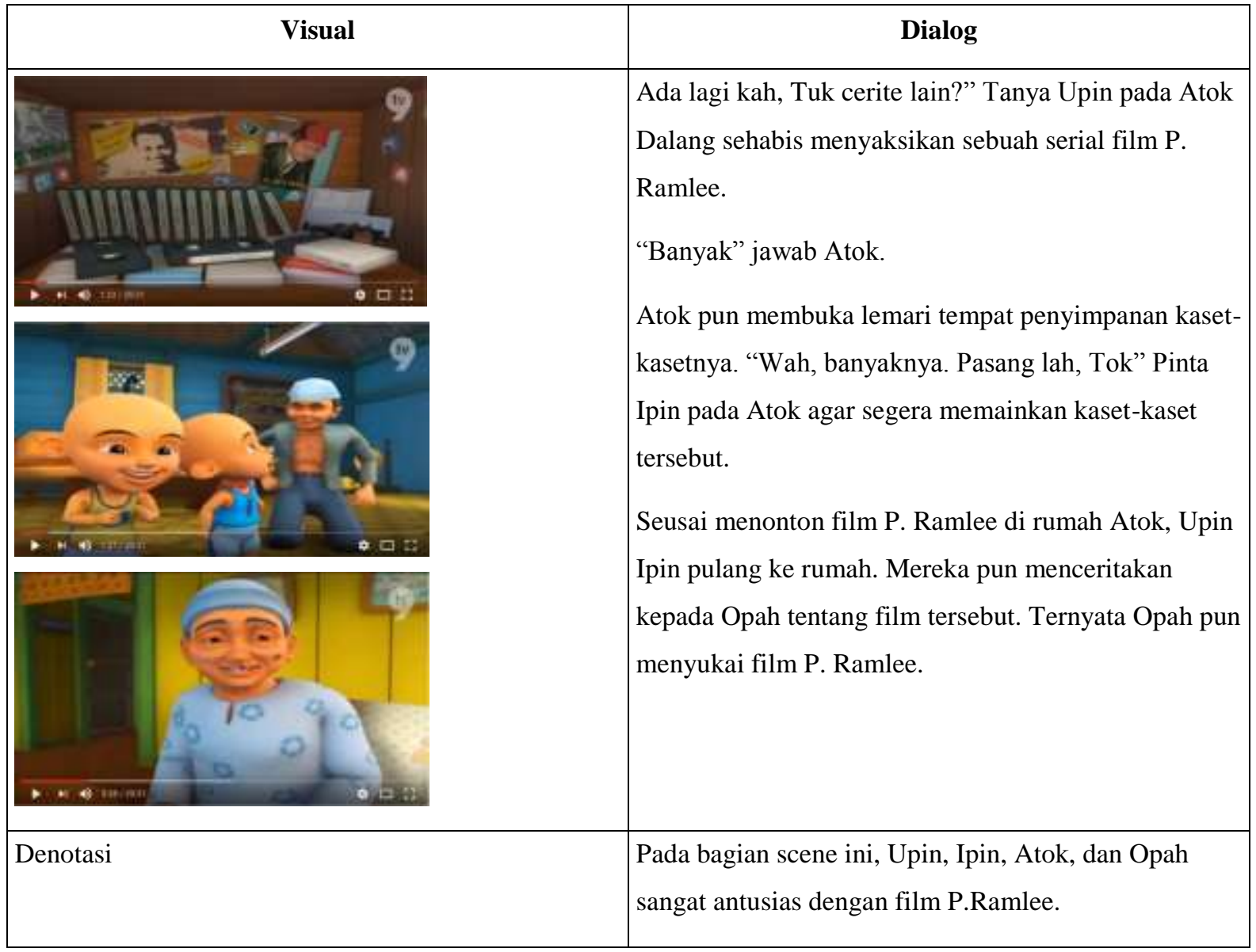




\begin{tabular}{|c|c|}
\hline Konotasi & $\begin{array}{l}\text { P. Ramlee merupakan artis Malaysia yang tersohor tak } \\
\text { hanya di negerinya, tetapi juga di Indonesia, terutama } \\
\text { di Aceh karena masih memiliki hubungan dengan } \\
\text { daerah di ujung barat Indonesia itu. P. Ramlee terlahir } \\
\text { dengan nama Teuku Zakaria bin Teuku Nyak Puteh di } \\
\text { Pulau Pinang, } 22 \text { Maret } 1929 \text {. Ia memiliki darah Aceh } \\
\text { karena sang ayah, Teuku Nyak Puteh, berasal dari } \\
\text { Lhokseumawe, sedangkan ibunya bernama Che Mah } \\
\text { Hussein, asli Malaysia. Ramlee kecil sudah meminati } \\
\text { dunia seni. Mulanya, ia suka bermain ukulele, lalu } \\
\text { beralih ke alat musik gitar dan biola. Ketertarikannya } \\
\text { pada bermusik, membuat ia bergabung dalam Orkes } \\
\text { Teruna Sekampung dan Sinaran Bintang Sore. Pada } \\
\text { 1947, ia menjuarai lomba menyanyi Radio Pulau } \\
\text { Pinang yang kemudian mengantarkannya menjadi } \\
\text { Bintang Penyanyi Utama Malaysia. Pada lomba itulah, } \\
\text { Teuku Zakaria menyematkan nama P. Ramlee, } \\
\text { kehingga kelak menjadi tenar. P merujuk pada nama } \\
\text { lalu menambah gelar Tan Sri pada nama P. Ramlee. } \\
\text { ayahnya: Puteh. Sejak saat itu (1947) ia dikenal } \\
\text { sebagai P. Ramlee hingga ajal menjemput pada } 29 \\
\text { Mei 1973, di usia } 44 \text { tahun. Chinta (1948) merupakan } \\
\text { film pertama yang diperankan P. Ramlee, berperan } \\
\text { sebagai penjahat dan penyanyi latar. Semasa hayatnya, } \\
\text { P. Ramlee membintangi } 66 \text { film. Tak hanya dikenal } \\
\text { sebagai pelaku seni peran, P. Ramlee juga dikenal } \\
\text { dengan lagu-lagunya, di antaranya "Zapin Malaysia", }\end{array}$ \\
\hline
\end{tabular}

Pada scene keempat, Upin \& Ipin dan teman-temannya melakukan dialog dan berdrama seperti yang terdapat pada film serial P. Ramlee dalam judul Anakku Sazali. Scene dilakukan pada teras rumah Tok Dalang. Analisis scene 4 disajikan pada tabel 4 . 
Tabel 4 Analisis Scene 4

\begin{tabular}{|c|c|}
\hline Visual & Dialog \\
\hline$x+4$ wing & $\begin{array}{l}\text { "Hoi dengar, aku punya banyak duit. Aku borak } \\
\text { (bohong) sama Daddy aku. Dia bagi aku duit, dia } \\
\text { sayang sama aku. Berapa banyak pun aku boleh } \\
\text { dapat” Kata Ehsan menirukan dialog peran Sazali } \\
\text { dalam film P.Ramlee. } \\
\text { "Kau tak tahu malu kah? Anak orang baik-baik } \\
\text { tingkah laku macam perompak? Kau ingat pasal } \\
\text { inikah bapak kau antar kau sekolah?” Sambung Tok } \\
\text { Dalang yang seolah-olah berperan sebagai ayah dari } \\
\text { Sazali” } \\
\text { "Sudah terlambat Pak. Bapak yang bersalah dalam } \\
\text { soal ini, bapak membesarkan Sazali dengan secara } \\
\text { membabi buta saja, segala apa kemahuan Sazali bapak } \\
\text { tunaikan. Segala apa hajat Sazali, bapak sempurnakan, } \\
\text { sehingga Sazali pandai cakap bohong sama Bapak. } \\
\text { Sehingga Sazali menipu Bapak, menipu untuk } \\
\text { kepentingan diri. Tetapi bapak hanya "Anakku Sazali” } \\
\text { kata Ehsan sambil menunjuk kearah Tok Dalang. }\end{array}$ \\
\hline Denotasi & $\begin{array}{l}\text { Scene ini memperagakan ulang film Anakku Sazali. } \\
\text { Film ini menceritakan seorang laki-laki yang bernama } \\
\text { Sazali. Sazali besar dengan Ayahnya. Ibunya } \\
\text { meninggal dunia sesaat setelah Sazali dilahirkan. } \\
\text { Ayahnya berjanji akan selalu menyayangi Sazali dan } \\
\text { selalu memaafkan kesalahan Sazali, sekalipun itu } \\
\text { fatal. Ketika Sazali beranjak dewasa, ia pun selalu } \\
\text { dimanja dengan dirayakan ulang tahunnya dan } \\
\text { dihadiahi barang mewah berupa sebuah mobil terbaru } \\
\text { yang mahal harganya. Sejatinya, di usia itu Sazali tak } \\
\text { pantas lagi untuk ditimang-timang. Dan ternyata } \\
\text { Sazali terpikat oleh sepupunya sendiri anak pamannya, } \\
\text { Pakcik Mansyur. Kejadian yang tidak diinginkan } \\
\text { terjadi. Sang sepupu hamil karena digagahi Sazali. } \\
\text { Ayahnya pun murka dan melabrak Sazali. Bukan } \\
\text { tanggung jawab yang Sazali berikan, ia malah } \\
\text { menyalahkan Ayahnya yang telah salah dalam } \\
\text { membesarkan dan mengasuhnya. Ayahnya terperanjat, }\end{array}$ \\
\hline
\end{tabular}




\begin{tabular}{|l|l|} 
Konotasi & $\begin{array}{l}\text { karena Sazali telah berlaku demikian karena } \\
\text { kesalahannya sebagai seorang bapak. Sazali } \\
\text { mengatakan bahwa apapun kesalahan yang telah ia } \\
\text { perbuat adalah mutlak kesalahan Ayahnya. }\end{array}$ \\
$\begin{array}{l}\text { Cerita film ini merupakan sebuah jawaban dari sebuah } \\
\text { realita kehidupan. Pola asuh anak yang baik akan } \\
\text { menciptakan anak yang baik pula. Pemberian nasihat } \\
\text { ataupun hukuman sesuai dengan perbuatan yang } \\
\text { dilakukan si anak akan memberikan efek jera padanya } \\
\text { agar tidak mengulangi perbuatannya. Jika tidak, maka } \\
\text { akan mengakibatkan tingkah laku anak yang sudah } \\
\text { keterlaluan semakin menjadi-jadi. Sebaliknya, } \\
\text { melakukan aksi pembiaran terhadap anak akan } \\
\text { mengakibatkan si anak menjadi buta hati dan } \\
\text { bertindak semena-mena tanpa memikirkan perasaan } \\
\text { dan nasib orang lain di sekitarnya. Namun, sebagai } \\
\text { seorang anak, sudah seharusnya berbuat baik serta } \\
\text { berbakti kepada kedua orang tua. }\end{array}$ \\
\hline
\end{tabular}

Pada scene selanjutnya diperlihatkan suasana di warung makan Paman Muthu. Disana sudah ada Paman Athong dan Tok Dalang yang sedang berbincang-bincang. Analisis scene 5 disajikan pada tabel 5.

Tabel 5 Analisis Scene 5

\begin{tabular}{|l|l|}
\hline \multicolumn{1}{|c|}{ Visual } & \multicolumn{1}{c|}{ Dialog } \\
\hline & $\begin{array}{l}\text { “Amboi Muthu, gembira nampak. Ada apakah?" } \\
\text { Tanya Tok Dalang pada Paman Muthu yang sedang } \\
\text { bernyanyi riang sambil membersihkan gerobak } \\
\text { jualannya. } \\
\text { "Hehe, tak ada" jawab Paman Muthu sambil tertawa. } \\
\text { "Hei Athong, apa rupa dalam bilik tuh?" tanya Tok } \\
\text { Dalang pada Paman Athong yang sedang memegang } \\
\text { sebuah peti yang terbuat dari kayu. "Eh Tok Dalang. } \\
\text { Ini petik antik. Kuncinya sudah hilang. Saya mau } \\
\text { buka, mana tau ada duit didalam" jawab Paman } \\
\text { Athong sambil menunjuk kearah peti kayu tersebut. } \\
\text { Tiba-tiba terdengar letusan. }\end{array}$ \\
\hline
\end{tabular}




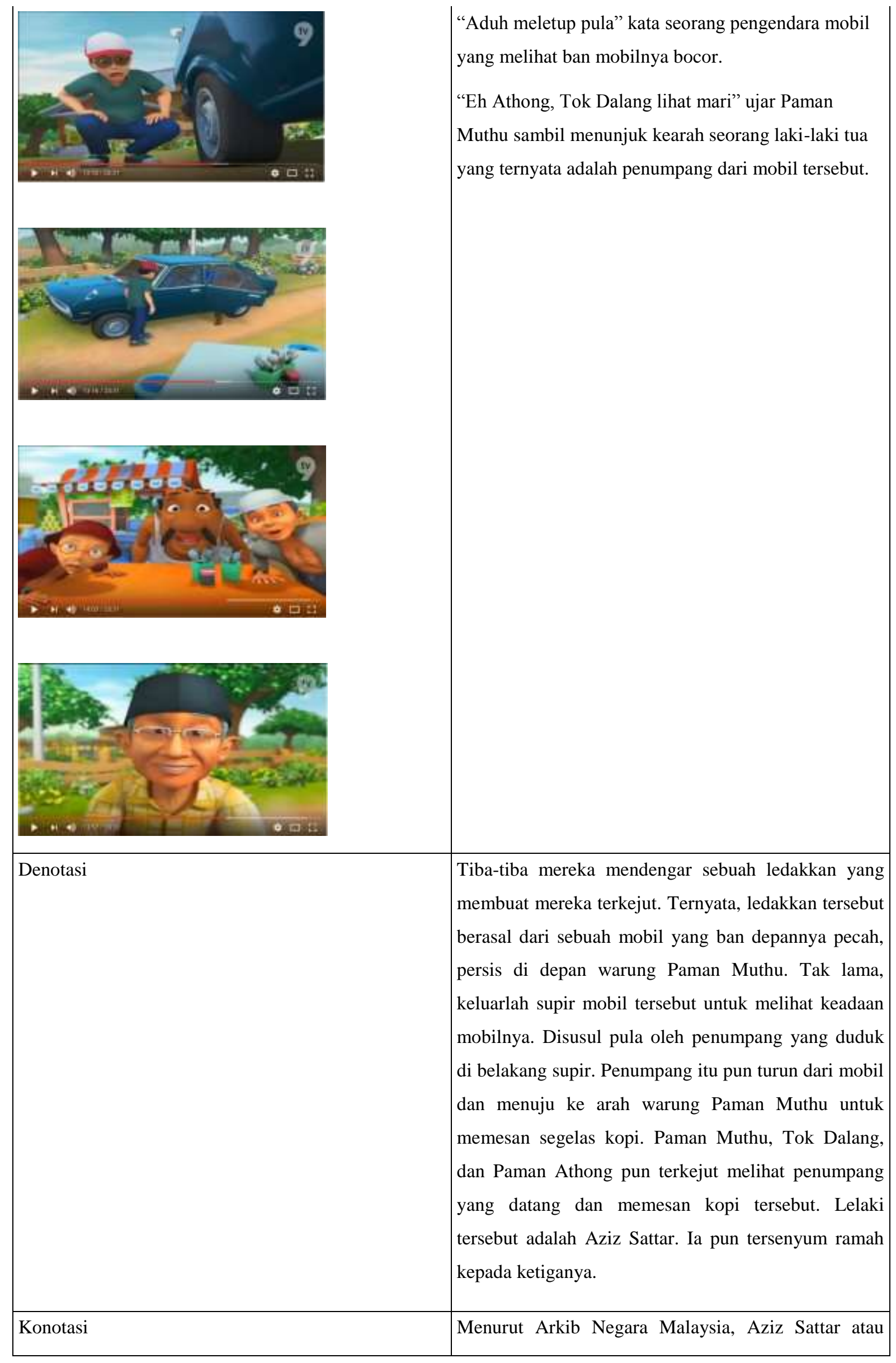

12 | Juprinedi et al.: Analisis Makna Denotatif dan Konotatif... 
Datuk Aziz Sattar, lahir pada Januari 1930 di Surabaya, Indonesia. Darah Indonesia yang dimilikinya berasal dari sang ayah. Datuk Aziz dibawa ayahnya ke Singapura ketika berumur tujuh tahun, dan bersekolah di Sekolah Melayu. Namun, sekolahnya terhenti karena adanya perang dunia kedua. Datuk Aziz semasa remaja pernah bekerja sebagai pemandu kereta. Ia tidak pernah malu bekerja sebagai buruh, selagi pekerjaan itu halal. Karir seni beliau berawal dari sebuah persahabatan dengan Sharif Dol yang bekerja di Studio Film Production. Beliau adalah penulis skenario, pemain film, dan sutradara yang sangat terekenal dalam dunia perfilman melayu kala itu. Akhirnya Datuk Aziz bermain dalam film perdananya pada tahun 1957 yang berjudul "Bujang Lapok" bersama dengan P. Ramlee. Sejak saat itu, namanya mulai dikenal oleh para masyarakat Malaysia, Singapura, dan Indonesia.

Scene keenam merupakan scene terakhir dalam film animasi Upin \& Ipin pada episode Kenangan Mengusik Jiwa. Analisis scene 6 disajikan pada tabel 6.

Tabel 6 Analisis Scene 6

\begin{tabular}{|l|l|}
\hline \multicolumn{1}{|c|}{ Visual } & \multicolumn{1}{|c|}{ Dialog } \\
\hline "Tok Aziz, mana P. Ramlee? suka tengok cerita dia" \\
kata Upin bertanya pada Aziz Satar. \\
"Suka ya?" tanya Aziz Satar. \\
"Suka, Suka, Suka" kata Ipin menjawab. \\
"P.Ramlee telah meninggal dunia tiga puluh Sembilan \\
tahun yang lalu, anak-anak. \\
\end{tabular}




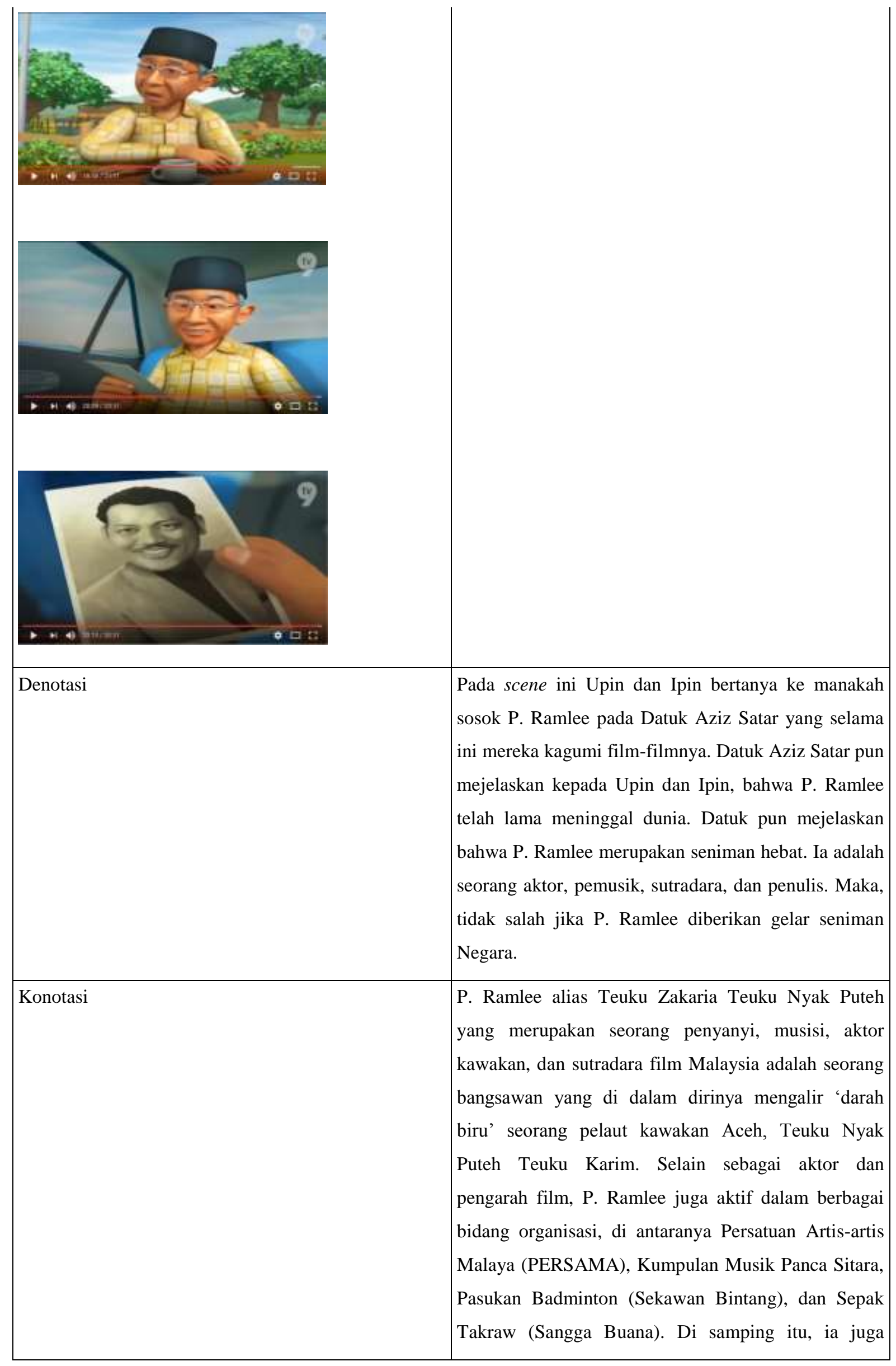

14 | Juprinedi et al.: Analisis Makna Denotatif dan Konotatif... 
pernah mengadu nasib di bidang perdagangan dengan menerbitkan majalah hiburan Bintang dan majalah Gelanggang Films. Bersama rekan-rekannya, ia pernah mendirikan dua buah perkumpulan film, yaitu Perusahaan Film Malaysia (PERFIMA) dan SAZARA Film Company. P. Ramlee juga sering diundang dalam forum-forum penting, di antaranya dalam Kongres Bahasa dan Persuratan Melayu Ketiga di Singapura dan di Johor Bahru (1956), dan Kongres Kebudayaan Kebangsaan di Universitas Malaya, Kuala Lumpur (1971). Semasa hidupnya, ia pernah berkunjung ke beberapa negara, di antaranya Indonesia, Hong Kong, Manila dan Tokyo. Film terakhir yang dibintangi sebelum ia menghembuskan nafas terakhir berjudul Laksamana Do Re Mi tahun 1972, sedangkan lagu dan lirik terakhirnya berjudul Ayer Mata di Kuala Lumpur pada tahun 1973. P. Ramlee meninggal dunia pada tanggal 29 Mei 1973 dalam usia 44 tahun, akibat serangan jantung. Jenazahnya dimakamkan di Tanah Perkuburan Islam, Jalan Ampang Kuala Lumpur, Malaysia. Ia meninggalkan sebuah rumah yang berada di jalan Depap yang telah dijadikan Pustaka Peringatan P.Ramlee pada tahun 1986. Selain itu, namanya telah diabadikan sebagai nama jalan di Pusat Bandar Raya Kuala Lumpur menjadi Jalan P. Ramlee (yang dulunya bernama Jalan Parry) pada tahun 1982. Tidak hanya di Malaysia, nama P.Ramlee ternyata juga sangat akrab di kalangan masyarakat Aceh, Indonesia. Dikutip dari laman peradabandunia.com, Organisasi antar bangsa Pusat Kebudayaan Aceh dan Turki (PuKAT) membuat sebuah acara Kenang Rindu untuk P Ramlee yang bertajuk "P. Ramlee: Anak Aceh Bintang Asia Tenggara". Acara ini dilaksanakan di Aceh Community (ACC) Sultan II Selim Banda Aceh pada tahun 2014 lalu. Selain itu, masyarakat Aceh juga sering memutar lagu-lagu ciptaan P. Ramlee.

Untuk menambah validitas penelitian, dilakukan pengujian dengan memberikan kuesioner yang berisi lima pertanyaan kepada 32 responden, dengan berbagai latar belakang pekerjaan seperti karyawan, mahasiswa, dan 
ibu rumah tangga, mengenai apakah masyarakat setuju dengan hasil analisis semiotika pada film animasi 3D Upin \& Ipin episode Kenangan Mengusik Jiwa. Rangkuman hasil kuesioner disajikan dalam tabel 7 berikut.

Tabel 7 Rangkuman Hasil Kuesioner

\begin{tabular}{|c|c|c|c|c|c|c|}
\hline No & Pernyataan & $\begin{array}{l}\text { Sangat } \\
\text { Setuju } \\
\quad(4)\end{array}$ & $\begin{array}{l}\text { Setuju } \\
\text { (3) }\end{array}$ & $\begin{array}{l}\text { Tidak } \\
\text { Setuju } \\
\quad(2)\end{array}$ & $\begin{array}{c}\text { Sangat } \\
\text { Tidak } \\
\text { Setuju } \\
\quad(1)\end{array}$ & $\begin{array}{l}\text { Interpretasi } \\
\qquad(\%)\end{array}$ \\
\hline 1 & $\begin{array}{l}\text { Analisis semiotika yang telah dibuat pada film } \\
\text { Upin \& Ipin ini dapat dipahami. }\end{array}$ & 26 & 6 & 0 & 0 & Baik $(95 \%)$ \\
\hline 2 & $\begin{array}{l}\text { Analisis semiotika pada setiap scene sudah } \\
\text { sesuai dengan masing-masing maknanya. }\end{array}$ & 23 & 8 & 0 & 1 & Baik $(91 \%)$ \\
\hline 3 & $\begin{array}{l}\text { Melalui metode semiotika, penonton mengerti } \\
\text { pesan moral yang disampaikan dalam film } \\
\text { animasi Upin \& Ipin episode Kenangan } \\
\text { Mengusik Jiwa. }\end{array}$ & 19 & 12 & 0 & 1 & Baik $(87 \%)$ \\
\hline 4 & $\begin{array}{l}\text { Melalui metode semiotika, masyarakat dapat } \\
\text { dengan mudah memahami setiap tanda/simbol } \\
\text { yang tersirat dalam menilai sebuah pesan moral } \\
\text { pada film animasi. }\end{array}$ & 19 & 13 & 0 & 0 & Baik $(89 \%)$ \\
\hline$* 5$ & $\begin{array}{l}\text { Scene yang dianalisis dengan metode semiotika } \\
\text { dalam film animasi ini masih terlalu sedikit. }\end{array}$ & 6 & 6 & 11 & 9 & $\begin{array}{l}\text { Cukup Baik } \\
(67,97 \%)\end{array}$ \\
\hline
\end{tabular}
menjadi (3), Sangat Tidak Setuju menjadi (4).

Penghitungan terhadap pertanyaan pertama dilakukan sebagai berikut:

Sangat Setuju (4): $26 \times 4=104$

Setuju (3): $6 \times 3=18$

Tidak Setuju (2): 0 × $2=0$

Sangat Tidak Setuju (1): $0 \times 1=0$

Jumlah $=122$

Jumlah skor ideal untuk pertanyaan 1 (satu) yang diajukan kepada responden yaitu:

a) Skor tertinggi : 4 × $32=128$ (Sangat Baik)

b) Skor terendah : 0 x $32=0$ (Sangat Kurang Baik)

Dari sini diperoleh interpretasi skor hasil pengamatan $(122 / 128)$ x $100 \%=95 \%$, yang masuk dalam kategori Baik. Melalui penghitungan yang sama, dari pertanyaan kedua, diperoleh interpretasi skor hasil pengamatan sebagai berikut: $(117 / 128)$ x 100\% =91\%, yang masuk dalam kategori Baik. Dari pertanyaan ketiga, diperoleh interpretasi skor hasil pengamatan sebagai berikut: (112/128) x 100\% =87\%, yang masuk dalam kategori Baik. Dari proses penghitungan pada pertanyaan keempat, diperoleh interpretasi skor hasil pengamatan sebagai berikut: $(115 / 128)$ x 100\% = 89\%, yang masuk dalam kategori Baik.

Interpretasi skor hasil pengamatan dari hasil penghitungan pertanyaan kelima yaitu (87/128) $\mathrm{x} 100 \%=$ 67,97\%, yang masuk dalam kategori Cukup Baik. Pertanyaan kelima merupakan pertanyaan berbentuk negatif sehingga indikator pada parameter penilaian berbanding terbalik dengan pertanyaan 1-4. Pada pertanyaan ini, 
nilai Sangat Setuju menjadi (1), Setuju menjadi (2), Tidak Setuju menjadi (3), dan Sangat Tidak Setuju menjadi (4). Pada pernyataan yang bernilai negatif, penghitungan menjadi sebaliknya; angka hasil penghitungan kecil menunjukan hasil "Sangat Baik" atau sangat setuju. Hasil interpretasi pada pertanyaan terakhir ini menunjukan bahwa responden cukup setuju; scene-scene yang penulis analisis sudah dapat dikatakan cukup, sehingga tidak dibutuhkan lebih banyak scene untuk memahami pesan moral yang disampaikan dalam film animasi ini.

\section{KESIMPULAN}

Setelah mendeskripsikan dan menganalisis hasil temuan data yang telah dikemukakan pada bab sebelumnya, maka penulis menarik kesimpulan sebagai berikut:

1. Film animasi Upin \& Ipin merupakan contoh film animasi hiburan yang bisa dijadikan pembelajaran dan diambil hikmahnya dalam cerita yang disampaikan pada episode Kenangan Mengusik Jiwa. Lebih lanjut, dari uraian serta analisis yang telah dipaparkan, inti cerita dalam film ini adalah jangan pernah melupakan sejarah maupun budaya yang telah ada sejak dahulu. Ribuan budaya yang telah kita kenal melalui sejarah tidak sepatutnya kita tinggalkan begitu saja. Sama halnya, cerita dalam film animasi Upin \& Ipin Kenangan Mengusik Jiwa membantu kita untuk kembali mengenang sosok budayawan dan seniman tersohor asal Malaysia, P. Ramlee. Meskipun beliau merupakan seniman asal negeri Jiran, beliau memiliki darah Indonesia yang berasal dari Ayahnya. Itulah mengapa kita harus ikut mengenang seniman berdarah Aceh tersebut. Ini menunjukkan sebuah penghormatan terhadap seniman-seniman lain yang mengikuti jejak P. Ramlee di Malaysia maupun di Indonesia.

2. Penonton sudah mulai mengerti maksud dari semiotika dan contoh-contohnya. Namun tidak semua mengerti mengenai unsur semiotika yang terdapat dalam film Upin \& Ipin. Beberapa di antaranya hanya mengerti arti dari semiotika namun tidak paham pada contohnya.

3. Dengan adanya metode semiotika, dapat memudahkan para masyarakat untuk mengetahui arti dan pesan moral yang disampaikan dalam setiap scene pada film maupun pada sebuah karya.

\section{DAFTAR PUSTAKA}

Anonim. (2010). http://www.arkib.gov.my/web/guest/datuk-aziz-sattar

Buana, S. (2009, Oktober 29). Adab Bertamu dan Memuliakan Tamu. Dikutip dari https://muslim.or.id/1546adab-bertamu-dan-memuliakan-tamu.html

Kurniawan. (2001). Semiologi Roland Barthes, Jakarta: Gramedia.

Rahmat P.S. (2009). Penelitian Kualitatif. Equilibrium, 5.

Rawung, L. (2013). Analisis Semiotika Pada Film Laskar Pelangi, Journal Acta Diurna, 1 (4).

Sobirin, N. (2015, September 21). Hang Tuah Pahlawan Melayu Yang Harus Bertarung Dengan Sahabat.

Dikutip dari https://daerah.sindonews.com/read/1046522/29/hang-tuah-pahlawan-melayu-yang-harusbertarung-dengan-sahabat-1442678504

Widyaningrum, S. (2012). Rasisme Dalam Film Fitnah. Skripsi. Yogyakarta: Jurusan Ilmu Komunikasi FISDIP Universitas Pembangunan Nasional "Veteran” Yogyakarta. 